\title{
Aspectos educacionais do ensino de filosofia
}

\section{Marcos Von Zuben}

A proposta de reflexão sobre os aspectos educacionais do ensino da filosofia nos coloca diante de uma pergunta que podemos formular nos seguinte termos: qual o papel da filosofia na formação das crianças, dos jovens, dos adultos? ou qual o valor educativo do discurso e da reflexão filosófica? Dessa forma, se coloca a questão sobre a prática de um discurso filosófico e seus efeitos educacionais sobre as pessoas que se iniciam nela.

Vê-se, de início, que a dimensão da formação do indivíduo já está implicada em uma reflexão desse tipo na medida em que nos remetemos precisamente aos efeitos formativos da filosofia sobre o indivíduo que a pratica. Precisamos, nesse sentido, manter aberta a pergunta: o que é formar-se? e o que faz com que a filosofia seja algo formativo?

Abordaremos essas perguntas percorrendo o caminho de algumas respostas dominantes apresentadas a essas questões ao mesmo tempo em que ressaltaremos os seus vínculos com as práticas correntes presentes nos modos de se ensinar filosofia hoje. Ressaltaremos, também, os vínculos que essas respostas possuem com um determinado conceito de formação e com uma determinada valoração e compreensão da vida no tempo. Em nossa trajetória, iremos nos aproximando de uma resposta que nos parece mais elucidativa.

A primeira resposta de que gostaria de lhes falar é aquela que pensa a educação filosófica como uma prática com um sentido moral que se vincula a ideais públicos hegemônicos nos dias de hoje como democracia, cidadania, pleno desenvolvimento, autonomia, etc.

Esses ideais constituem-se como uma representação moral da sociedade, da comunidade e da pessoa humana. Representação que coloca o ensino de filosofia como independente de qualquer finalidade instrumental, utilitária, técnica ou puramente econômica. Esses são papéis da ciência e das artes técnicas, mas não da filosofia que possui, assim, valor educativo em si mesma, qual seja, formar a pessoa moral e política. Essa perspectiva tem como sustentação a primazia do futuro sobre o passado e o presente, onde a formação é vista como desenvolvimento em direção ao futuro ideal. O passado não nos serve de modelo e o presente não nos é suficiente e precisamos, portanto, nos aproximar continuamente desses ideais criticando o passado $e$ as formas de dominação presentes. Educar para uma nova pessoa moral, para um novo mundo cuja representação já está constituída, trata-se de implementá-la, de desenvolvê-la.

Como exemplo do sentido que toma o ensino de filosofia é o que notamos em práticas do tipo ensinar cidadania, direitos e deveres, o respeito a propriedade 
individual, o respeito ao próximo. Tudo, inclusive, expresso em leis do tipo Parâmetros Curriculares Nacionais, que tem como base a lei maior da educação brasileira como a Lei de Diretrizes e Bases da Educação Nacional. - LDB, que estabelecem, em seus temas transversais, o ensino da cidadania, valor capital das sociedades de Estado Democrático de Direito. Essas são práticas bastante freqüentes nos ensinos fundamental e médio.

Diante dessa primeira resposta, a prática do ensino da filosofia volta-se, então, para a legitimação institucional de valores hegemônicos atuais. $\mathrm{O}$ ensino da filosofia torna-se, aqui, instrumento de dominação, prática ingênua de domínio cultural. Neste ensino de filosofia, tudo já está constituído, estamos tão seguros de nossa pessoa e de nossa cultura que supomos a nós mesmos como uma medida segura e um critério de todas as coisas, cessa a pergunta fundamental, trata-se somente de pensar como implementar os ideais do já sabido e do já dito.

O equívoco dessa resposta se faz notar, como um sintoma, na tensão percebida hoje entre esse ideal moral e as práticas educacionais crescentes de racionalização técnica e utilitária da educação. Assim, ao contrário do que é propagado, resulta o ensino da filosofia no reforço da lógica dominante na sociedade industrial.

A segunda resposta que gostaria de lhes falar pensa a prática do ensino da filosofia como a posse de uma erudição, como a posse de um saber histórico produzido pela tradição de nossa cultura ocidental. Neste caso, ser filosoficamente educado já não se refere mais a formação no sentido de transformação dos sujeitos, em resultado de uma prática que visa desenvolvê-los, mas em uma relação exterior, em um saber que não toca, não modifica o próprio sujeito. Têm-se uma utilidade disfarçada, filosofia como o gozo na condição de possuir algo, mas que não é útil para a vida, a não ser por seu efeito de status; uma utilidade que se refere à posição social do sujeito, um status obtido por se saber possuidor de conhecimentos que poucos possuem, como possuir uma obra de arte, uma função importante, um corpo esbelto que nos torna especiais, superiores do ponto de vista social.

Em "Ecce Homo" Nietzsche descreve o erudito como aquele que "acaba por perder integra e totalmente a capacidade de pensar por conta própria. Se não revolve livros, não pensa. Responde a um estímulo (um pensamento lido) quando pensa, ao final a única coisa que faz é reagir. O erudito dedica toda a sua força a dizer sim ou não, à crítica de coisas já pensadas - ele mesmo já não pensa...O instinto de autodefesa abrandou-se nele; em caso contrário defender-se-ia contra os livros" (Nietzsche, 1971, p. 50)

Aprender filosofia é aprender conhecimentos técnicos da tradição do pensamento. A valorização excessiva do passado se dá em função do seu valor presente, de uma fruição presente, nada podendo garantir quanto ao futuro, o futuro não importa, não tem valor.

O erudito encontramos não no ensino fundamental e médio, mas nas universidades, onde, citando Nietzsche em "O porvir de nossas escolas", ele "é 
semelhante ao operário da fábrica, que durante toda a sua vida não faz outra coisa que determinado parafuso e determinada mangueira, para determinado utensílio ou determinada máquina, no que indubitavelmente chegará a ter incrível maestria" (Nietzsche, 1977, p. 112) . Não só hoje, mas outrora, essa tem sido a marca registrada do ensino de filosofia nas universidades, intensificado pelo crescente domínio tecnológico da vida contemporânea, como podemos perceber, ainda citando Nietzsche " essa erudição que se poderá comparar com a inchação hipertrófica de um corpo doente. Os institutos são os lugares onde se transplanta essa obesidade erudita, quando não degeneraram até o ponto de converterem-se nas palestras dessa elegante barbárie que hoje pode pavonear-se com o nome de "cultura alemã da época atual" (id. p. 114-5)

A terceira resposta que gostaria de indicar é aquela que pensa o ensino de filosofia como apreensão de verdades universais sobre o homem, sua realidade, seu futuro, onde o papel da educação filosófica é conduzir os sujeitos em busca da verdade; formar-se é encontrar essas verdades escondidas, mascaradas, ocultadas, ideologizadas, conscientizar os sujeitos é desvendar-lhes o livro da verdade, o livro sagrado escritos por iluminados; educar-se filosoficamente é ir de encontro a um produto acabado, um saber objetivo, como as ciências, produzido por filósofos ou correntes filosóficas geniais.

Esta formação se fixa nas respostas já dadas, já estabelecidas em algum lugar da tradição, o valor está no passado, no já dito e no já pensado por outros, mas não em toda a tradição como o erudito, mas em uma determinada tradição; o presente e o futuro são conseqüências de um feliz encontro no processo formativo do indivíduo, o encontro dessas verdades. A ênfase está nas respostas e as eventuais perguntas cumprem a função de esclarecer e reforçar o já sabido, simples função interpretativa.

Essa perspectiva produz dogmatismo, anula o espaço de abertura da pergunta filosófica em direção ao sujeito e ao mundo; trata-se simplesmente de um esforço do sujeito já constituído em encontrar a resposta certa e implementá-la no mundo. Aprender filosofia é encontrar a bússula, o guia para orientar os modos de pensar, de sentir e de agir no mundo.

Enquanto prática de ensino filosófico, esta resposta encontra seu lastro também na academia com toda a sua diversidade de ismos, istas, para todos os gostos, com suas formações analíticas, marxistas, fenomenológicas, existencialistas, hermenêuticas, desconstrutivistas, bem ao modo das seitas dogmáticas. Em seu "Zaratustra", Nietzsche adverte aqueles que buscam um caminho a seguir: "Por muitos caminhos diferentes e de muitos modos cheguei eu à minha verdade, não por uma única escada subi até a altura onde meus olhos percorrem o mundo. $\mathrm{E}$ nunca gostei de perguntar por caminhos - isso a meu ver sempre repugna! Preferiria perguntar e submeter à prova os próprios caminhos. Um ensaiar e perguntar foi todo o meu caminhar - $e$, na verdade, também tem de responder a tal perguntar! Esse é o meu gosto, não um bom gosto, não um mau gosto, mas meu gosto, do qual não me envergonho e não o escondo. Esse é meu caminho - onde 
está o vosso? Assim respondia eu aos que me perguntavam "pelo o caminho". O caminho, na verdade, não existe" (Nietzsche, 1998, p. 272).

A quarta e ultima resposta que gostaria de apresentar minhas oposições é aquela que compreende a prática do ensino de filosofia como a satisfação das demandas convencionais e triviais da atualidade, onde aprender filosofia é estar preparado para a conversa sobre temas atuais que a grande massa se sente atraída a falar ou porque lhes é agradável ou porque se refere a problemas percebidos coletivamente e que todos se sentem atraídos por eles e que tem como característica o fato de ser um discurso geral sobre clichês de uma época.

Formar ou educar o sujeito significa torná-lo um especialista na elaboração do sentido comum e da boa consciência. Sua característica é produzir um discurso em que todos se reconheçam e se afirmem através dele. A ênfase está na resposta, a pergunta é mero adereço, e as vezes nem precisamos pronunciá-la, pois ela já está subentendida na profusão de respostas convencionais, é o fim do perguntar na filosofia.

Sua prática educativa se constitui a partir da discussão de temas "candentes" da atualidade como moda, aborto, sexo, drogas, relação pai e filho, etc., refletidos sob a perspectiva do "politicamente correto", bem ao modo das práticas hoje bastante presentes no ensino de filosofia nos níveis fundamental e médio.

Ensinar filosofia se resume a venda de um produto atrativo ao mercado consumidor de obviedades. Não está em questão nem o sujeito que questiona nem o mundo, pois não há efetivamente questionamento.

O que faz, então, com que a filosofia seja algo formativo, algo educativo? Se a educação filosófica produzir sujeitos eruditos, nem prosélitos, nem moralistas, nem pessoas satisfeitas, o que seria então?

A filosofia produz um modo de interrogação que é uma relação consigo mesmo, uma relação de abertura para consigo, como interrogação aberta sobre si. Penso que o que está em questão é o próprio sujeito que interroga. Diferentemente dos outros tipos de interrogação que podemos efetuar em campos específicos do saber como na ciência, nas artes, no lazer, no trabalho, na educação, na religião, a interrogação filosófica se dirige contra a própria condição de formação do sujeito, põe em questão sua própria constituição na medida em que é o trabalho reflexivo de desconstituição do sujeito formado, conformado, determinado. Ainda quando a pergunta filosófica se dirige ao mundo, é o sujeito que questiona que está em questão.

Educar-se filosoficamente é desfazer-se da própria vida para construir a própria vida, sair do campo da determinação de si para possibilitar o indeterminado, abrir espaço para criar a própria vida, é a abertura à indeterminação. Perder-se de si, para encontrar-se a si como um ser de possibilidades. 
Assim, o valor do passado está no esquecimento do passado, pois nosso passado é, de alguma forma o que nos determina, mas ao mesmo tempo precisamos dele para esquecer dele, para tornar possível, no presente, a construção do novo e não a repetição do mesmo.

Educar-se filosoficamente é o exercício e a prática de deseducar-se eternamente. Construção de si implica, como contraparte necessária a destruição de si.

Termino minhas palavras com uma pequena passagem do "Zaratustra" bastante conhecida: "Inocência é a criança, e esquecimento, um novo começo, um jogo, uma roda que gira por si mesma, um movimento inicial, um sagrado dizer "sim". Sim meus irmãos, para o jogo da criação é preciso dizer um sagrado "sim": o espírito, agora, quer sua vontade, aquele que está perdido para o mundo conquista o seu mundo" (Nietzsche, 1998, p. 53).

Referências bibliográficas:

NIETZSCHE, F. Sobre el porvenir de nuestras escuelas. Barcelona : Tusquets, 1997.

. Assim falou Zaratustra. Rio de Janeiro : Civilização Brasileira, 1998.

Ecce Homo. Madrid : Alianza, 1971. 